\title{
Servant Leaders as Change Agents
}

\author{
Janice P. Tanno \\ Walden University \\ David K. Banner \\ Walden University
}

Servant leadership (SL) produces high performance and employee engagement. Non-SL senior leaders lacking business ethics have caused negative outcomes. This study explored the lived experiences of senior leaders' decision-making in SL organizations. Maslow's theories, decision theory, spirituality, Cicero's virtue theory of ethics; SL comprised the theoretical/conceptual foundation. Data collection used purposive sampling of 18 senior leader participants in SL organizations employing Giorgi's descriptive psychological structures of experiences analysis method. Findings confirmed ethical decision-making in SL organizations. Recommendations included examining CEO ethical leadership and firm performance interrelations and promoting ethical decision-making at all levels. Conclusions supported teamwork as the one structure of experience. Positive social change implications are an ethical capitalism that occurs by building community and SL organizations.

Keywords: servant leaders, organizational change agents, servant leadership, service, ethics, empowerment, decision-making, communication, teamwork

\section{Introduction}

This article focuses on servant leaders as change agents. Over the past 30 years, scandals have erupted in organizations that have revealed a lack of ethical decision-making by too many senior leaders. Environmental and social concerns have become prevalent for all organizational leaders. These concerns involve global warming and environmental abuses that have shown a lack of corporate social responsibility (Mele \& Sanchez-Runde, 2013). Further concerns have included a lack of vision and ethics, corporate greed, Wall Street malfeasance, globalization, and resultant economic crises that have further increased distress (Renand, 2015; Yazdani \& Murad, 2015).

Many leaders have been documented who, through an apparent lack of ethical and effective leadership, have failed their institutions, their stakeholders, other leaders, and their managers, workers, and communities. Universal problems such as bullying, abuse of power, unethical and corrupt practices, toxic emotions, social isolation, alienation in the workplace, poor work-life balance, and other issues of employees' psychological well-being have continued to perplex organizational leaders (Gaddis \& Foster, 2013; Sendjaya, 2007). The collapse of Enron, Arthur Andersen, WorldCom, Tyco, and other companies across the globe have demonstrated these chronic problems.

\section{Background}

The background of this study is the discipline of leadership. A lack of consistent business ethics in decision-making by leaders has become problematic for contemporary organizations. Business ethics 
is not a new concept. Both the ancient Greeks, the foremost thinkers in this area, and the Romans wrote about moral duty and ethics (Small, 2013). Cicero (106-64 BC), a businessman, lawyer, politician, and orator, became a philosopher and wrote Moral Duties (De Officiis) to illustrate his view of practical wisdom and how to be an ideal business leader by practicing the four cardinal virtues (Mele \& Sanchez-Runde, 2013). Cicero's stance was that once a businessperson comprehended the social fellowship of humanity, one could be ethical and prosper at the same time (Small, 2013). Cicero's virtue theory of ethics and the servant leadership (SL) philosophy share imperatives of honorable and beneficial conduct - the goal of business ethics is to be honorable. The ideal business leader by being honorable has a beneficial life. Both honorable and beneficial imperatives are moral and advocate for the common good rather than self-interest.

Currently, attention in the field of leadership has shifted to a lack of business ethics when leaders make decisions. Leadership is about principles. Five guiding leadership principles are decisionmaking, people, strategy, productivity and self-improvement (Burian, Burian, Maffei, \& Pieffer, 2014). SL is other-oriented, caring, and inspiring leadership. By serving others, servant leaders transcend individual self-interest (Parris \& Peachey, 2013). SL is the one leadership model that has both spiritual and ethical components (Greenleaf, 1977, 2002). Sendjaya (2007) maintained that spirituality is the precursor to ethics. This phenomenological study addressed a gap in the literature on the lack of ethical leadership and business ethics in decision-making by senior leaders in organizations. The study is important in offering a greater understanding of the lived experiences of senior leaders in SL organizations and closing the gap in the literature.

\section{Literature on Servant Leaders as Change Agents}

Servant leaders empower and nurture their followers to grow professionally and personally. In the process, followers often become servant leaders. The most effective leaders seek to make a difference in the lives of others (Keith, 2008; Lynch \& Friedman, 2013). The compelling message in Greenleaf's (1970) essays on SL is that leaders should serve with talent, compassion, and courage and that followers respond positively to competent servants as leaders.

\section{Servant as Leader}

The servant as leader and leader first are considerably different; both leader types are extreme (Greenleaf, 1977, 2002). The servant first demonstrates that leaders serve people's highest priority needs. A natural servant is most likely to persevere and improve ideas about what serves another's highest priority needs, comparing directly with Maslow's $(1968,2000)$ hierarchy of needs, selftranscendence, and eupsychian management theories. Inspiration (insight) is a precursor to going out ahead to lead the way, the very essence of leadership noted Greenleaf. To lead requires initiative, ideas, structure, risking failure, and the opportunity for success. The leader has a plan, vision, and a big dream to strive toward, thus to become like Maslow's $(1968,2000)$ on becoming toward enlightenment (Greenleaf, 1977, p. 29). But the key here is that vision reflects the follower's perspectives and needs. The one who states this purpose establishes trust. The leader should have confidence, expertise, and entheos (i.e., a sustaining spirit) to encourage followers to pursue the dream (Greenleaf, 1977, 2002).

Other key aspects of a natural servant are listening and understanding. Learning to listen first is an acquired discipline with practice (Frick, 2011). The servant leader practices acceptance and empathy showing tolerance of other's imperfections (Sipe \& Frick, 2015). A servant as leader should be creative which often involves delving into the unknown. Intuition provides insight into the unknown through patterns that allows one to generalize based on past events (Greenleaf, 1977, 2002). The 
greater gift of intuition is the conceptual understanding that forms a sound basis for decisionmaking. A growing body of social science knowledge has framed ethical thought (i.e., decisionmaking) and behavior as driven by intuition (Weaver, Reynolds, \& Brown, 2014).

The principal ethic of leadership is foresight (Greenleaf, 1977, 2002). Foresight is forecasting what will happen and when (Greenleaf, 1977, p. 38). A leader must have faith that the needed experience, expertise, and intuitiveness will emerge to achieve optimal performance in each situation. A severe moral compromise is the inability to act when an opening exists, noted Greenleaf (1970). Without foresight, the leader loses the lead and is a leader in name only. Foresight, awareness, and perception increase a leader's effectiveness. Effective leaders are keenly aware and concerned types who possess serenity that allows creativity to flourish (Greenleaf, 1977, 2002; Keith, 2008; Sipe \& Frick, 2015; Spears, 2004). A mark of a servant as leader is persuasion, which is the preferred method of motivation-gentle, clear, persistent persuasion, not coercion. The ability to conceptualize is a prime leadership talent. Highly creative individuals conceptualize a uniquely appropriate role to play; drawing on their strengths, they decide what is undeniably right for their time and place in life (Greenleaf, 1970, 1977).

In the context of SL and servant as leader, healing means to make whole. Implicit between the servant as leader and the follower is a subtle communication that the search for wholeness is something they share (Greenleaf, 1977, 2002; Keith, 2008; Maslow, 2000; Rohr, 2013). Regarding wholeness, Laloux's (2014) work about reinventing organizations consists in part of wholeness and authenticity that identifies a SL organization as an integral level green organization moving toward a teal organization. Teal is where taming the ego occurs.

For instance, the pluralistic green level is about service to others. Green Breakthrough 1 is about empowerment. Senior and middle managers become servant leaders (Laloux, 2014, p. 32). Results in pluralistic green organizations are often spectacular. Examples are Southwest Airlines and Ben and Jerry's. The family is the guiding metaphor (pp. 32-34).

Teal is a holistic approach to knowing, Sapientia, striving for wholeness in the wisdom tradition (Laloux, 2014) that equates to transcending ego boundaries to actualize inspired leadership. In today's world egos, fears, ambitions, and desires frequently rule individual's lives. By practicing meditation, yoga, martial arts, and walking to find that quiet place allows the inner voice of the soul to speak its truth and guidance, noted Laloux. Mindfulness meditation allows a leader to appreciate the changing nature of reality and begin to let go of overidentification with certain views or outcomes (Gelles, 2015). The availability of mindfulness meditation via the Internet is unprecedented. Thus, the potential implications are far reaching (Frizzell, Hoon, \& Banner, 2016). Teal holism is comparable to Maslow's (2000) sixth tier of the hierarchy of needs, where self-transcendence occurs. Greenleaf's $(1970,1977,2002)$ depiction of the servant as leader is most often a self- actualized individual moving toward a more holistic self-transcendent leader.

The 10 characteristics that define a servant leader (Spears, 2010) are listening, empathy, healing, awareness, conceptualization, foresight, persuasion, stewardship, commitment to growth, and community building. Servant leaders empower and nurture their followers to grow both professionally and personally. Followers often become servant leaders in the process. The most effective leaders seek to make a difference in the lives of other people and do not seek fame, wealth, or power (Keith, 2008). Ironically, when they make a difference they receive power, wealth, and fame and use them as means to help others. The key practices identified for the effectiveness of servant leaders are self-awareness, listening, changing the pyramid, developing one's colleagues, coaching instead of controlling, unleashing the energy and intelligence of others, and foresight, noted Keith. 
SL emphasizes serving people first, being a skilled communicator through listening, inviting feedback, collaboration, trust, empathy, systems thinking, and the ethical use of power. The objective is to enhance the growth of individuals in the organization and increase teamwork and personal involvement (Sipe \& Frick, 2015).

Correspondingly, Spears $(2004,2010)$ maintained that the servant leader is tough-minded and unflinching; that Greenleaf's (1977, 2002) servant leader is a servant of the organizational learning process. Both Spears and Greenleaf claimed the strongest organization is the one that has the largest voluntary action in support of its goals. The staff does the right thing at the right time to enhance full effectiveness with clear, comprehensive, well-understood goals, noted Spears.

Greenleaf's vision of the institution expanded to those working within an organization or business. Highly competitive business organizations are the least expected sector of society to act as a servant and where the most substantial change can occur (Greenleaf, 1977).

\section{Organization as Servant}

Once an organization becomes people building, people are first. Consequently, right actions to achieve distinguished excellence happen quickly. Distinguished excellence is the most desirable goal, noted Greenleaf (1977, 2002). A premise of organizational distinguished excellence is that a culture insistent on justice and love will provide an innovative opportunity (Maslow, 2000; Small, 2013). How to accomplish this goal is by working from within existing organizations stimulating actions that increase the capacity to serve and perform as a servant (Greenleaf, 1977, p. 9).

Keith (2008), a former CEO of The Greenleaf Center for Servant Leadership and an experienced manager/leader in various sectors of industry, education, and philanthropy, made a case for SL, elaborating on 13 aspects that lead to effectiveness. Keith developed a service-versus-power model designed to make a better world. The model articulates the how and why of SL. Keith, as well as Lynch and Friedman (2013), argued as advocates of SL, claiming how service is a cornerstone of the SL philosophy. The service model places service to others as the top priority. Serving others includes the employees, customers, stakeholders, and community. Servant leaders continuously strive to be trustworthy, self-aware, humble, caring, visionary, empowering, relational, competent, good stewards, and community builders (Keith, 2008; Greenleaf, 1977, 2002; Spears, 2004, 2010).

Servant leaders are characteristically self-reliant types who also show commitment to organizational goals. The transforming leader seeks out potential motives in followers, seeking to satisfy their higher needs and engage the whole person as a follower. The difference in the models is that the servant leader lives the service model of leadership, while the leader first or nonservant leader lives the power model of leadership (Keith, 2008). Servant leaders have a vision for the future and communicate the desired direction of the organization regarding its mission, values, and beliefs. They are then classified into attainable goals that serve as inspiration for the big picture. Thus, servant leaders maintain the progress of the people and the organization at its core (Boone \& Makhani, 2012). Service is a common theme in organizations, whether not-for-profit organizations, for-profit businesses, or communities. The desire to serve comes from a call—spirit first (Greenleaf, 1977, 2002).

The servant leader is the best leader to take the organization through change (Keith, 2008). Servant leaders will not use organizational change as a reason to build their power or make changes based on personalities, factions, and competition between rivals. Power is a gift from those who trust the leader consistent with Greenleaf's $(1977,2002)$ depiction of legitimate power. Correspondingly, AlHaddad and Kotnour (2015) created a roadmap to change management literature along with 
definitions to describe change types, enablers, and methods. Change has become the norm for organizations to obtain sustainable success and in the constantly changing global business world. Many approaches to managing change exist. Still, the problem is organizations undergoing change vary in structure, systems, strategies, and human resources. Al-Haddad and Kotnour's (2015) research enables leaders and managers to define and classify organizational change then select a method for systematic change and change management.

Dialogue (the ability to see other points of view and engage in thoughtful discourse towards a creative end) is helpful clarifying and practicing SL. It is a specific competency associated with the practice of servant leaders, a means to engage about injustices at the societal level, and a primary value that secures the foundation of SL development. At its core, the dialogue is constructive of SL itself. These intersections present a new way of thinking about connections between dialogue and SL. Four intersecting themes are (a) exhibiting humility, (b) building community, (c) demonstrating courage, and (d) modeling integrity and authenticity. The servant leader who maintains an understanding of and expertise in dialogue will be well prepared to positively influence and support others within the rapidly shifting and increasingly diverse landscape of our global society (Gigliotti \& Dwyer, 2016).

\section{Primus en Pares (First Among Equals)}

Houglum (2012) commented how primus en pares intersects well with complexity theory. The typical organizational hierarchical pyramid inverts in SL. The primus is a servant leader who embodies wholeness, autonomy, freedom, and wisdom. The primus helps others in actualizing their potential to become more like a servant leader. The team functions through a cocreative relationship instead of positional or legitimate power (van Dierendonck, 2011), noted Houghlum. The servant with the gifts, traits, and skills necessary for the situation will emerge to be the temporary primus.

Eventually, a new primus will emerge, sapiently (a sapiential leader is one who leads because he or she has the knowledge for that leadership situation), as challenges, goals, and other dynamics evolve with shared leadership. Teams and knowledge sharing are integral components of SL (Song, Park, \& Kang, 2015). SL is a long-term, transformational approach to the individual leader and society. The focus of SL is on how a servant leader completes outcomes, which is critical for understanding (Houghlum, 2012).

\section{Values/Virtues}

The key features used to measure leader's level of SL practice involve listening, empathy, and healing (Spears, 2014). To have empathy, one must have compassion. With a view toward healing, becoming whole, one must aspire to possess or intrinsically experience the ensuing values and virtues.

\section{Compassionate love}

Van Dierendonck and Patterson (2015) introduced compassionate love as an antecedent for SL. Compassionate love maybe a cornerstone for SL that helps deepen the motivation to serve. Love can be as mysterious as leadership itself, and yet there is something powerful about the components of love that compel both the leader and follower. Compassionate love is about doing well with a clear motivation of concern for the followers. Agape love is unselfish moral love (i.e., the Greek term for moral love) that centers on doing the right thing for the good of the other. Compassion provides hope and emotional healing. Compassionate leaders are gentle, innovative, and collaborative. A compassionate leader's skill is the ability to listen. 


\section{Listening as a skill}

Most servant leaders are excellent listeners and stay close to their colleagues (Frick, 2011; Sipe \& Frick, 2015); they are other-oriented and understand what colleagues need for high performance. Frick found that servant leader listening requires a commitment to listening to one's self first. Selflistening demands awareness, openness to transformation, and a willingness to transcend personal ego to understand others. To be a good listener, one must have empathy, be present, ask clarifying questions, and mirror ideas, feelings, and emotions. For effective leadership communication is essential and begins with listening, reflecting, questioning, and understanding the meaning of the language both verbally and nonverbally (Frick, 2011). The consensus among authors is that listening is first a necessary value/virtue to be an able, effective servant leader.

\section{Ethics and integrity}

A good, moral life, according to virtue ethics, is a life responsive to the demands of the world (Storsletten \& Jakobsen, 2015). Honesty, altruism, compassion, fairness, courage, and humility are prevalent values in SL. Proponents of SL contend that leaders whose behaviors reflect these values will be more effective. Likewise, in the pursuit of organizational ethics, top leaders should act as role models by demonstrating ethical leadership, before requiring employees to engage in ethical work behaviors (Shin, Sung, Choi, \& Kim, 2015). Ethics and integrity are vital to team building and effective leadership. The ability to serve effectively and build trust is contingent on ethical leadership.

Servant leaders inspire others and work diligently to better society. Servant leaders achieve results for organizations by giving priority to the needs of their followers and to those whom they serve. A good leader knows the way, directs followers to identify serious problems to solve and provides the risk-taking paradigm for the organization to follow. Good leaders recognize and reward success, thus, people feel like they belong to an organization that cares. Consequently, work becomes intrinsically motivating and meaningful (Rohr, 2013). Leaders transform people through organizational cultures that foster growth. A primary goal of the servant leader is to develop future servant leaders. One way is through ethics. Through the process of moralization, followers perceive leaders as ethical (Fehr, Yam, \& Dang, 2014). Trust is not given but earned by honorable business leaders who demonstrate ethical behavior through honesty and being forthright with their customers and constituents (Prentis \& Igoni, 2016).

\section{Servant Leadership Behaviors and Attitudes}

Yoshida, Sendjaya, Hirst, and Cooper (2014) were the first to conduct research to develop and test a multilevel framework assessing leader behavior, the mediating psychological processes, and contextual influences that simultaneously foster both employee creativity and team innovation. Servant leaders display a sustained, altruistic commitment to help followers grow and act as primus en pares (first among equals). Power becomes a means to serve as the leaders put the good of those led over self-interest. Hence, both serving and leading becomes virtually interchangeable (van Dierendonck, 2011). SL requires subordination of leader's goals for the greater good of the team and organization.

Likewise, Amah's (2015) quantitative study confirmed that for SL to be effective in leader-member exchange, motivation to serve must be high. The primary motive for the servant leader is to serve followers to make them willing and interested in organizational goals by improving their productivity. Maula-Bakhsh and Raziq (2016) found that sharing power and authority with subordinates and followers will yield a positive effect as power and authority will generate satisfaction with life along cognitive dimensions. Consequently, empowerment by the servant leader 
might increase the subjective well-being of employees. Strong evidence exists for a positive relationship between SL and satisfaction of the psychological needs of autonomy, competence, and relatedness. The more a leader behaves as a servant leader, the more followers feel their basic psychological needs are met (Chiniara \& Bentein, 2016).

Moreover, what servant leaders do is develop quality relationships, build community, seek feedback in making decisions, reach consensus and focus on personal development of employees. They also demonstrate egalitarian relationships with employees, discover ways to help, participate in community service projects, and give back to the community (Spears, 2010). The servant leader's focus is to help people achieve their goals by coaching and mentoring individuals to do their best. The leader's role is to coach and teach individuals so that they can excel. By serving well a leader serves the employees and they, in turn, increase their commitment and quality of work, which serves customers well. The result is customers enjoy the service, value the company, and both the reputation and profits of the company soar (Vinod \& Sudhakar, 2011).

Employee attitudes, management and leader/follower attitudes relevant to organizational settings and SL have been explored in the current literature. Boone and Makhani (2012) researched whether a leader has the necessary attitudes to implement SL. They questioned, "Is the SL style right for you?" Findings showed that SL can be an effective style to influence a group toward achieving organizational goals if a leader possesses or simply adopts these attitudes. First, to believe that visioning is not everything, but is the beginning of everything, that listening is hard work requiring a large investment of personal time and effort and is worth it. The job is about being a talent scout, committing to the staff's success, knowing that giving away power is good, and knowing that one is a community builder (Boone \& Makhani, 2012).

However, SL contributes to desirable attitudes and behaviors and psychological climates in the workplace. Still, gaps exist in the literature for further research on task performance, life satisfaction, and employee engagement. Future research should explore the effects of apathetic and negative attitudes and behaviors toward SL in organizational settings. Lastly, servant leaders are the best leaders to create change both individually and organizationally. As Keith (2008) aptly stated, the servant leader is the best leader to take an organization through change.

\section{Method}

The purpose of this phenomenological study was to identify and report the lived experiences of senior leaders regarding their ethical decision-making in SL organizations in the southwestern United States. Interviews with a purposive sample of participants in SL organizations that met Greenleaf's (1977, 2002) criteria took place to discover participant perceptions and lived experiences of SL. The sample consisted of three self-proclaimed SL organizations in the southwestern United States. Participants included 18 individuals who were the senior leaders of these organizations. A field test of the research questions and the interview guide was conducted with a university panel of scholarly experts on qualitative phenomenology. Face-to-face interviews were conducted at the three organizations' sites averaging from $32 \mathrm{~min}$ to $45 \mathrm{~min}$ with a few at $60 \mathrm{~min}$.

\section{Results}

The purpose of a descriptive analysis is to understand the meaning of the description based only on what is present in the data descriptive. Giorgi's $(2009,2012)$ descriptive phenomenological psychological data analysis steps (Figure 1) follow next. 


\section{Descriptive Phenomenology Psychological Data Analysis}

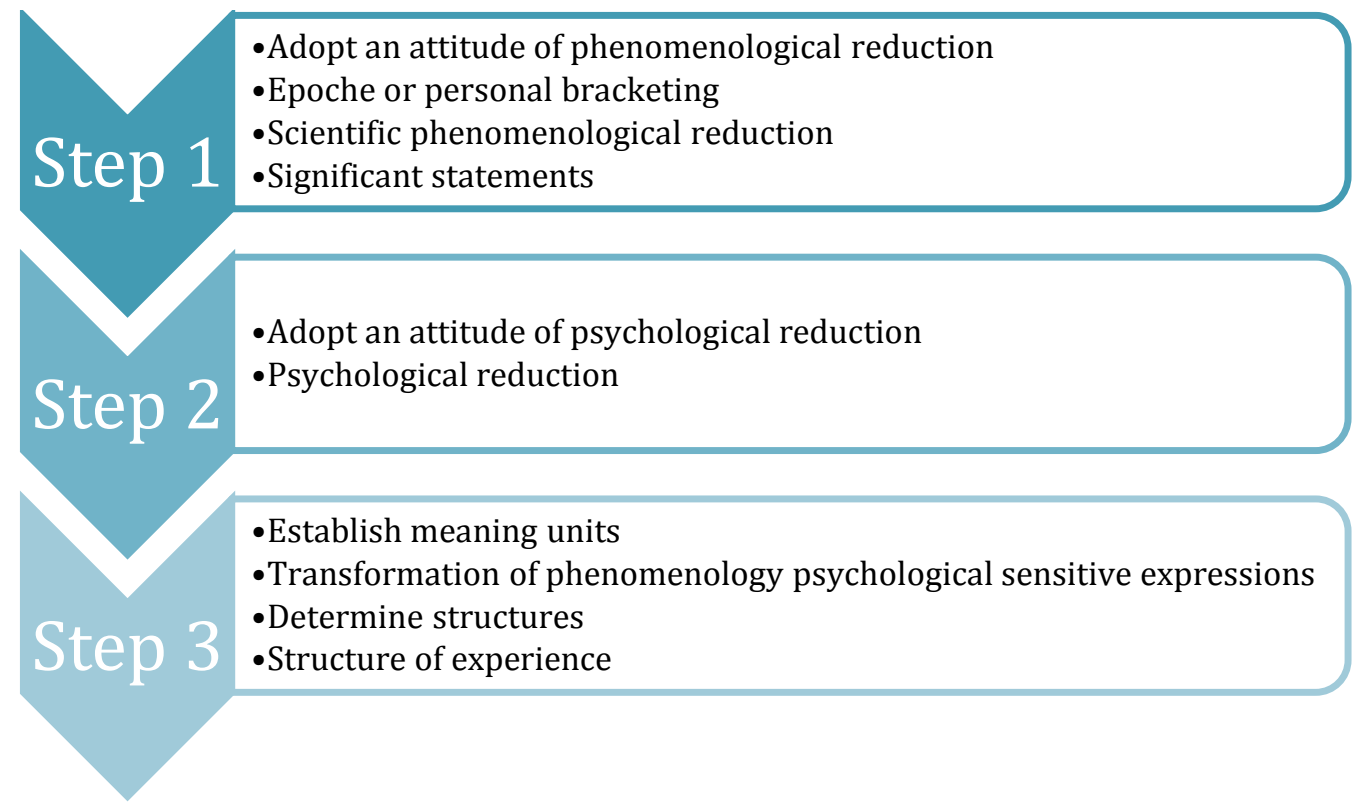

Figure 1. Descriptive Phenomenology Psychological Data Analysis Process

Ten themes with subcategories and quotes to support the relationships to the central research question, interview questions, as well as tables and a chart to display the responses, relationships, and frequencies are displayed in Table 1 . The 10 descriptive themes show the frequency and percentage of the participant's verbatim responses in each of the three SL organizations. Participant's lived experiences and perceptions were chosen based on quotes from the interviews that correlated with the themes for each interview question. For this article, there are six pertinent themes regarding organizational change that include representative participant data. 
Table 1. Thematic Results of the Study

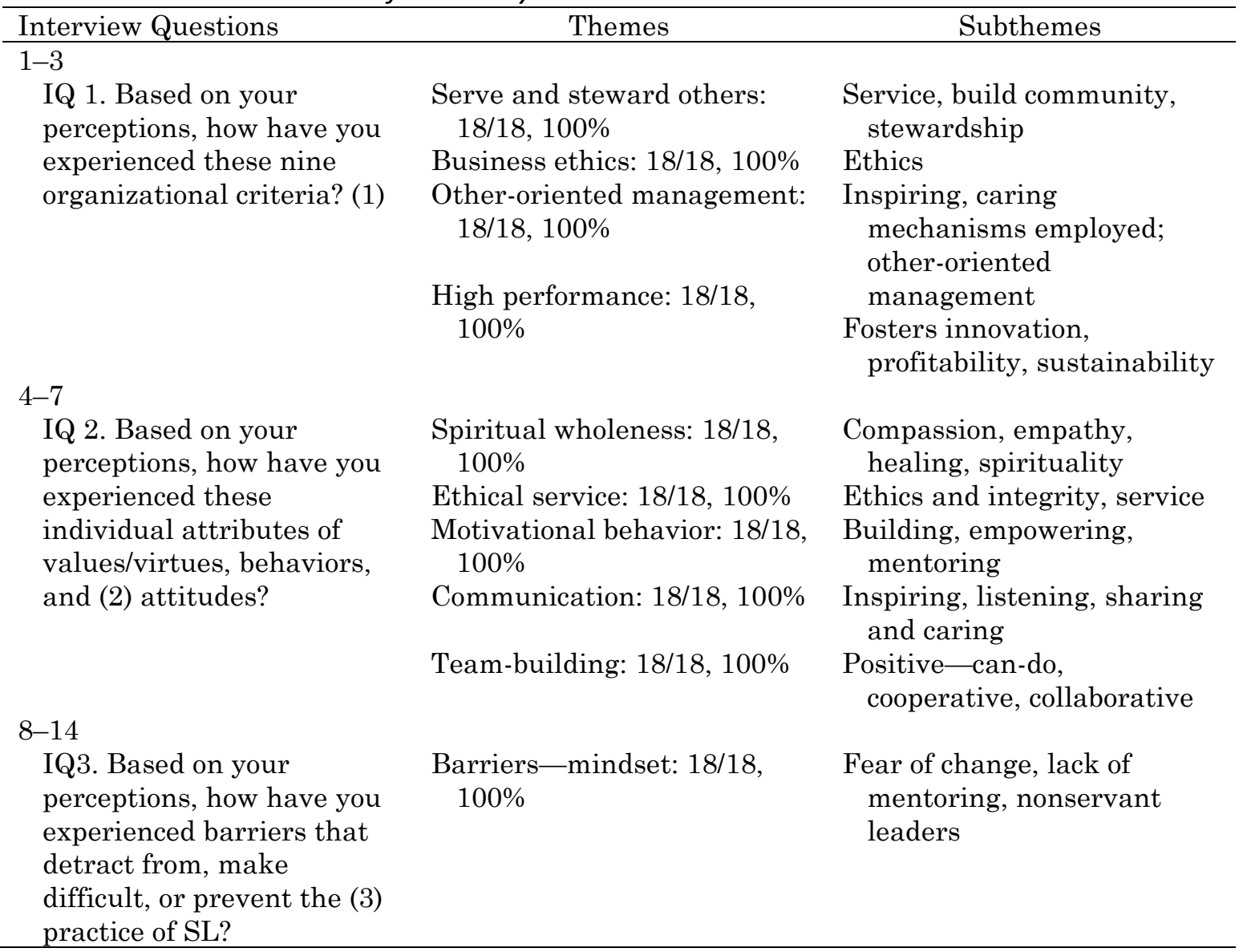

Note. SL = servant leadership. (1), (2), (3): See Interview Guide in Appendix.

\section{Serve and steward others}

All 18 (100\%) participants expressed the importance of serving others first and being a good steward. As one participant explained,

The gifts of time, talents, and treasures that are a fundamental part of any faith-based or human-based gift are alive and well here and are demonstrated by those that are served as well as those that give the service and that's what is often reciprocal. Often people will say to me, D . . . I came to serve but I got so much more back than I gave. And so, that is the epitome of the gift of stewardship.

Service and serving others' highest priority needs equates to "who we are" as an organizational identity. The service culture is "what we do" (Gioia, Patvardhan, Hamilton, \& Corley, 2013). Serving others' highest priority needs was viewed as a common core mission in line with the values and beliefs of the organization (Boone \& Makhani, 2012). A service and stewardship culture allows leaders and employees to make decisions to engage in the creation of the culture and a vision of how to implement it at each level of the organization (Desjardins \& Baker, 2013). 


\section{Business ethics}

All 18 (100\%) participants expressed the importance of business ethics. One participant described a meaningful example of ethics based on her lived experience:

It's doing the right thing even when it was not the easy thing to do. I think all of us have gone out of our way to do the right thing. The situation may be a little more difficult for us but, I can say that each one of the leaders that I interact with has done the same thing. Each one of us will stand our ground and have a good fight if we feel that is the right thing to do. None of us bow down, no, we would do what's needed to make sure we do the right thing.

Ethics begin with leadership. Competent leadership is necessary to establish a code of ethics and remain ethical. The four cardinal virtues of wisdom, justice, courage, and temperance form the basis of moral behavior and define the ideal business leader (Aßländer, 2013; Small, 2013). The factors that encourage ethical behaviors including ethical decision-making and the role of moral competencies by the decision maker are important to understanding (Morales-Sanchez \& CaballoMedina, 2013).

\section{Other-oriented management}

All 18 (100\%) participants expressed other-oriented management as employee engagement that creates a culture of inspiring, caring and sharing. Another participant stated,

We have a culture of caring and sharing. I think inspiring is the way that you are going to lead others. You can only influence and inspire. What we most have in common is that we do genuinely care about the people we're in business with and what their needs are first.

The concept of working in two teams, one conceptual and the other operational, fosters autonomy and the ability to make decisions. Eupsychian management (Maslow, 2000) is other oriented and fosters group and teamwork based on the spirituality of the leader perceived by leaders and employees.

\section{High performance}

All 18 (100\%) participants expressed that the senior leaders accepted the SL tenets and the importance of their reputation in the community. One participant commented,

Here, we do the right thing. When you do the right things, your reputation grows. Our reputation in the community is so important. We strive to make sure that everyone has a very good experience when they come here. Our sustainability affects our reputation on how we treat people. We are always going to do the right thing by our patients. That's how we are so sustainable. Why we keep growing at such a rapid rate has a lot to do with how we treat people.

Goodwill in the context of corporate reputation occurs because of a willingness to serve the community. CEO ethical leadership works through an ethical organizational culture that promotes firm performance if there is a strong corporate ethics program in place (Eisenbeiss, Knippenberg, \& Fahrbach, 2015). Ethical senior leaders are ethical leaders or extraordinary persons in general, perhaps both. Their focus is not only on short-term maximization of financial profit but also on caring for the well-being of other stakeholders. 


\section{Motivational behaviors}

All 18 (100\%) participants expressed motivational behaviors as the ability to empower others, to make necessary changes, and to build community by mentoring one another. One participant commented that empowerment is very prevalent on the campus from the CEO down. He's given the vice presidents the ability to empower, to change, and to build.

The servant leader puts the good of others over self-interest: Thus, power becomes a means to serve others. Empowerment from the servant leader has a positive effect on the well-being of employees (Maula-Bakhsh \& Raziq, 2016). Fostering employees' sense of control over their work by delegating authority and autonomy empowers them to make decisions.

\section{Team building: Primus en pares}

All 18 (100\%) participants expressed the importance of team building and first among equals. Another participant stated,

We are working in teams. Every single thing that a department does has an effect on another department, and eventually, affects the patient. We have started doing continuous improvement projects within the center to make sure that all the stakeholders are involved when we make decisions. We are very high on doing continuous improvement and are building on that culture of collaboration and cooperation.

Working in teams creates a culture of collaboration and cooperation and helps others to grow. Communication within an organization ensures that the members of each department are aware of their effects on other departments and ultimately to the clients they serve. To build a culture of collaboration, it is important to involve all stakeholders in the decision-making process.

\section{Discussion}

Findings supported the nine organizational criteria derived from Greenleaf's SL philosophy and Maslow's (2000) self-actualization and self-transcendence theories in service to others and a cause greater than self. Cicero's virtue theory of ethics (Aßländer, 2013; Small, 2013) is supported by business ethics in the need to establish ethical standards. Decision theory, a formula for making good decisions, is supported by the need for ethical decision-making in acts of service and in leadership situations to attain high performance. Decisions that employ probability theory under uncertainty often are intuitively made (Weaver et al., 2014) and filter options rapidly (Steele \& Stefansson, 2015).

Regarding high performance, Waterman (2015) asserted that Adam Smith's ideas were relevant to the modern world because of his pioneering economic ideas. Ideas that now incorporate into contemporary economics and conceivably provide the original classic defense of capitalism. The goal of capitalism is to provide goods and services that enhance the general welfare. The byproduct of this service is profit, one criterion of high performance. To serve and to steward others, practice business ethics, to inspire, care and share by employing other-oriented management, and to achieve high performance as an organization was perceived by all the senior leader participants as the organizational criteria for the practice of SL. Motivational behaviors were supported by Maslow's hierarchy of needs, to belong, to know, and to share with others. And, self- transcendent leaders who build, empower, and mentor others to attain individual and organizational goals (Spears, 2010). Decision theory (Steele \& Stefansson, 2015) is supported in the individual attributes defined by Greenleaf as they require ethical decision-making by the senior leaders to motivate and lead others based on the ethical use of power, trust, and doing the right thing (Sipe \& Frick, 2015). 


\section{Limitations}

The study design was a descriptive phenomenological psychological approach involving 18 senior leaders of self-proclaimed SL organizations in the southwestern United States. Generalizing the results to other geographic locations could be a limitation based on the cultures and locations of other self-proclaimed SL organizations. Study demographics included only senior leaders in selfproclaimed SL organizations. Only self-proclaimed SL organizations were eligible to participate in this study. Purposive sampling and a small sample size were a limitation to the generalizability of the study. Replication of the study results may differ in other organizations and with larger sample sizes.

\section{Recommendations}

Opportunities for future research exist in the field of leadership, specifically, Greenleaf's SL philosophy including the nine organizational criteria, individual attributes of virtues/values, behaviors and attitudes employed in this study. Opportunity for future research exists on the foundational theories of the study and how they correlate with leadership and organizational change. An abundance of research on the different constructs of SL exists as well as literature on decisionmaking. The paucity of research on all the constructs of SL in this study and the problem of the lack of ethical leadership, specifically, the problem of lack of consistency in senior leaders' decisionmaking are opportunities for further research.

Furthermore, future research should employ Cicero's virtue theory of ethics to develop moral competencies in leaders to encourage ethical decision-making. Encourage future researchers to examine the interrelation of CEO ethical leadership and firm performance (Peterson, Galvin, \& Lange, 2012). Future researchers should empirically test the servant identity (Sun, 2013) by analyzing the decision-making processes of servant leaders in various situations. Future research exists to explore the relationships of CEO attributes, various forms of leadership and firm performance regarding ethical service (Eisenbeiss et al, 2015). Future researchers should examine theory building on the 10 characteristics of a servant leader. Team building plays a vital role in board governance (Charas, 2015) and in leadership and operational management for organizational effectiveness (Hamidi \& Gabrielsson, 2014). Future research warrants examining the role of ethics in team leadership and decision-making at the board and operational levels.

\section{Implications for Social Change}

The potential to create positive social change is related to how senior leaders perceive themselves in SL organizations working with others and in making consistent ethical decisions for the common good. Their role as a senior leader is to serve and to steward others to help them grow and excel in their positions in the organization so that the goals and objectives of the organization are met. Building community among others within the organization, mentoring and empowering others to make decisions, to be and do their best is a mark of the senior leader practicing stewardship as shared leadership in the SL organization.

Service is integral to the behavior of the leader often manifested as a call or desire to serve. By serving others is how things got done (Greenleaf, 1977). Greenleaf was a process expert. The potential for positive social change in senior leaders who practice SL is that they either are or become process experts and change agents (Keith, 2008). The result is effective leadership at all levels to bring the organization to distinction and high performance. Often, the servant leader is perceived as a spiritual individual or a spiritual individual perceived as a servant leader. Spirituality 
is integral to the philosophy of serving others as a higher purpose to self-actualize and transcend self in pursuit of reality and truth. Senior leaders' decision-making may improve considerably by consistently practicing business ethics in everyday leadership situations. Senior leaders may experience behaviors of ethical service and integrity and act as a role model for others to emulate.

On the organizational level, more organizations may adopt the practice of SL. Organizations that experience interim and prolonged organizational change could realize positive social change-an increase in social capital, innovations, creativity, and improved workplace environments by employing senior leaders who consistently make ethical business decisions. An increase in collaborative teamwork could occur by building trust due to consistent ethical decision-making by senior leaders. Because SL has universal appeal, senior leaders' competencies with this style of leadership could meet the needs of globalization. The findings may be transferable to other organizations and provide information for senior leaders, executives, and managers about what the lived experiences of senior leaders in SL organizations reveal. Positive social change results in a type of ethical capitalism by building community and SL organizations.

\section{Conclusions}

This study captured the lived experiences of senior leaders in self-proclaimed SL organizations in the southwestern United States. The one structure of experience that prevailed throughout this study is Teamwork. The meaning of teamwork is analogous to the functioning family. The family in a SL organization has a leader, the primus, who knows the way, fosters an environment of serving others needs first and stewardship of time, talent, and treasure and the organization. Decisions are made ethically with other family members for the common good. The members of the family are empowered to become the best they can be and mentored to do good works within the family community and the greater community.

The community is an extension of the family where alliances and partnerships are made to thrive and to build a better world. The leaders and members act ethically, are interdependent and help one another in support of the goals and objectives of the family organization. The ideal family is profitable, sustainable, and innovative marked by high performance. The method for success is collaboration, cooperation, sharing and inspiring each other to work in teams to reach individual and organizational goals. No one has absolute power as leadership is shared by the members of the family. The family creed is to serve and to lead from the heart.

\section{References}

Aßländer, M. S. (2013). Honorableness or beneficialness? Cicero on natural law, virtues, glory, and (corporate) reputation. Journal of Business Ethics, 116, 751-767. doi:10.1007/s10551-0131819-7

Al-Haddad, S., \& Kotnour, T. (2015). Integrating the organizational change literature: A model for successful change. Journal of Organizational Change and Management, 28, 234-262. doi:10.1108/JOCM-11-2013-0215

Amah, O. E. (2015). Servant leadership relationship with leader-member exchange: The moderating role of motivation-to-serve and motivation-to-lead. International Journal of Management, Economics, and Social Sciences, 4, 108-127.

Boone, L. W., \& Makhani, S. (2012). Five necessary attitudes of a servant leader. Review of Business, $33,83-96$. 
Burian, P. E., Burian, P. S., Francis, R., \& Pieffer, M. A. (2014). Principles driven leadership: Thoughts, observations, Management \& Information Systems, 18, 1-10. doi:10.19000/ijmis

Charas, S. (2015). Improving corporate performance by enhancing team dynamics at the board level. International Journal of Disclosure and Governance, 12, 107-131. doi:10.1057/jdg.2013.35

Chiniara, M., \& Bentein, K. (2016). Linking servant leadership to individual performance: Differentiating the mediating role of autonomy, competence, and relatedness need satisfaction. The Leadership Quarterly, 27, 124-141. doi:10.1016/j.leaqua.2015.08.004

Desjardins, C., \& Baker, M. (2013). The leadership task model. Journal of Applied Leadership and Management, 2, 17-39.

Eisenbeiss, S. A., van Knippenberg, D., \& Fahrbach, C. M. (2015). Doing well by doing well? Analyzing the relationship between CEO ethical leadership and firm performance. Journal of Business Ethics, 128, 635-651. doi:10.1007/s10551-014-2124-9

Fehr, R., Yam, K. C., \& Dang, C. (2014). Moralized leadership: The construction and consequences of ethical leader perceptions. Academy of Management Review, 40, 182-209. doi:10.5465/amr.2013.0358

Frick, D. M. (2011). Greenleaf and servant-leader listening. Westfield, IN: The Greenleaf Center for Servant Leadership.

Frizzell, D. A., Hoon, S., \& Banner, D. K. (2016). A phenomenological investigation of leader development and mindfulness meditation. Journal of Social Change, 8, 14-25. doi:10.5590/JOSC.2016.08.1.02

Gaddis, B. H., \& Foster, J. L. (2013). Meta-analysis of dark side personality characteristics and critical work behaviors among leaders across the globe: Findings and implications for leadership development and executive coaching. Applied Psychology, 64, 25-54. doi:10.1111/apps.12017

Gelles, D. (2015). Mindful work: How meditation is changing business from the inside out. Retrieved from http://www.amazon.com/Mindful-Work-Meditation-Changing-Business

Gigliotti, R. A., \& Dwyer, B. (2016). Cultivating dialogue: A central imperative for the study and practice of servant leadership. Servant Leadership: Theory and Practice, 3, 69-88.

Gioia, D. A., Patvardhan, S. D., Hamilton, A. L., \& Corley, K. G. (2013). Organizational identity formation and change. The Academy of Management Annals, 7, 123-193. doi:10.1080/19416520.2013.762225

Giorgi, A. (2009). The descriptive phenomenological method in psychology: A modified Husserlian approach. Pittsburgh, PA: Duquesne University Press.

Giorgi, A. (2012). The descriptive phenomenological psychological method. Journal of Phenomenological Psychology, 43, 3-12. doi:10.1163/156916212X632934

Greenleaf, R. K. (1970). The servant as leader. Indianapolis, IN: The Robert K. Greenleaf Center.

Greenleaf, R. K. (1977). Servant leadership: A journey into the nature of legitimate greatness and power. Upper Saddle River, NJ: Paulist Press.

Greenleaf, R. K., \& Spears, L. C. (2002). Servant leadership: A journey into the nature of legitimate power and greatness. Mahwah, NJ: Paulist Press. 
Hamidi, D. Y., \& Gabrielsson, J. (2014). Developments and trends in research on board leadership and systematic literature review. International Journal of Business, Governance and Ethics, 9, 3. doi:10.1504/IJBGE.2014.064739

Houglum, D. T. (2012). Myth-busters: Traditional and emergent leadership. E:CO, 14, 25-39. Retrieved from https://www.psycholosphere.com/Myth\%20Busters\%20\%20traditional\%20and\%20emergent\%20leadership\%20by\%20Houglum\%202012.pdf

Keith, K. M. (2008). The case for servant leadership. Westfield, IN: Greenleaf Center for Servant Leadership.

Laloux, F. (2014). Reinventing organizations: A guide to creating organizations inspired by the next stage of human consciousness. Brussels, Belgium: Nelson Parker.

Lynch, J. A., \& Friedman, H. H. (2013). Servant leader, spiritual leader: The case for convergence. Journal of Leadership, Accountability and Ethics, 10, 87-95.

Maslow, A. H. (1968). Toward a psychology of being (2nd ed.). New York, NY: D. VanNostrand Company.

Maslow, A. H. (2000). The Maslow business reader (D. D. Stephens, Ed.). New York, NY: John Wiley and Sons.

Maula-Bakhsh, R., \& Raziq, A. (2016). Development of conceptual link between servant leadership and employee subjective well-being. Journal of Applied and Emerging Sciences, 4, 157-168.

Mele, D., \& Sanchez-Runde, C. (2013). Cultural diversity and universal ethics in a global world. Journal of Business Ethics, 116, 681-687. doi:10.1007/s10551-013-1814-z

Morales-Sanchez, R., \& Cabello-Medina, C. (2013). The role of four universal moral competencies in ethical decision-making. The Journal of Business Ethics, 116, 717-734. doi:10.1007/s10551013-1817-9

Parris, D. L., \& Peachey, J. W. (2013). A systematic literature review of servant leadership theory in organizational contexts. Journal of Business Ethics, 113, 377-393. doi:10.1007/s10551-012$1322-6$

Peterson, S. J., Galvin, B. M., \& Lange, D. (2012). CEO servant leadership: Exploring executive characteristics and firm performance. Personnel Psychology, 65, 565-596. doi:10.1111/j.17446570.2012. 01253.x

Prentis, E. L., \& Igoni, S. E. (2016). Leadership: A case study on the importance of ethics and trust. Journal of Business, 1, 1-14. doi:10.18533/job.v1i3.22

Renand, F. (2015). Genuine leadership and the global financial crisis. International Journal of Peace and Development Studies, 6, 10-20. doi:10.5897/IJPDS2010.014

Rohr, R. (2013). Breathing under water: Spirituality and the twelve steps (2nd ed.). Cincinnati, OH: St. Anthony's Messenger Press.

Sendjaya, S. (2007). Transcendental spirituality: Development and validation of a new spiritual leadership measure. Journal of Management Studies, 34, 2-23.

Shin, Y., Sung, S. Y., Choi, J. N., \& Kim, M. J. (2015). Top management ethical leadership and firm performance: Mediating role of ethical and procedural justice climate. Journal of Business Ethics, 129, 43-57. doi:10.1007/s10551-014-2144-5

Sipe, J., \& Frick, D. (2015). Seven pillars of servant leadership. New York, NY: Paulist Press. 
Small, M. W. (2013). Business practice, ethics and the philosophy of morals in the Rome of Marcus Tullius Cicero. Journal of Business Ethics, 115, 341-350. doi:10.1007/s10551-012-1401-8

Song, C., Park, R. K., \& Kang, S. (2015). Servant leadership and team performance: The mediating role of knowledge-sharing climate. Social Behavior and Personality, 43, 1749-1760.

Spears, L. C. (2004). Practicing servant leadership. Leader to Leader, 2004, 7-11. doi:10.1002/1tl.94

Spears, L. C. (2010). Servant leaders: They share 10 traits. Personal Excellence, 15, 1-14.

Steele, K., \& Stefansson, H. O. (2015). Decision theory. In E. N. Salta (Ed.), The Stanford encyclopedia of philosophy. Stanford, CA: Stanford University. Retrieved from http://plato.stanford.edu/archives/win2015/entries/decision-theory/

Storsletten, V. M. L., \& Jakobsen, O. D. (2015). Development of leadership theory in the perspective of Kierkegaard's philosophy. Journal of Business Ethics, 128, 337-349. doi:10.1007/s10551014-2106-y

Sun, P. Y. T. (2013). The servant identity: Influences on the cognition and behavior of servant leaders. The Leadership Quarterly, 24, 544-557. doi:10.1016/j.leaqua.2013.03.008

van Dierendonck, D., \& Patterson, K. (2015). Compassionate love as a cornerstone of servant leadership: An integration of previous theorizing and research. Journal of Business Ethics, 128, 119-131. doi:10.1007/s10551-014-2085-z

Vinod, S., \& Sudhakar, B. (2011). Servant leadership: A unique art of leadership. Interdisciplinary Journal of Contemporary Research in Business, 2, 456-464.

Waterman, A. M. C. (2015). Moral philosophy or economic analysis? The Oxford handbook of Adam Smith. Review of Political Economy, 27, 218-229. doi:10.1080/09538259.2015.1021147

Weaver, G. R., Reynolds, S. J., \& Brown, M. E. (2014). Moral intuition: Connecting current knowledge to future organizational research and practice. Journal of Management, 40, 100129. doi:10.1177/0149206313511272

Yazdani, N., \& Murad, H. S. (2015). Toward an ethical theory of organizing. Journal of Business Ethics, 127, 399-417. doi:10.1007s/10551-014-2049-3

Yoshida, D. T., Sendjaya, S., Hirst, G., \& Cooper, B. (2014). Does servant leadership foster creativity and innovation? A multi-level mediation study of identification and prototypicality. Journal of Business Research, 67, 1395-1404. http://dx.doi.org/10.1016/j.jbusres.2013.08.013 


\section{Appendix}

\section{The Interview Guide}

Welcome: Hi, I am Jan. So nice to meet you. Is the room comfortable? This is a consent form to participate in this study. Do you still want to participate? Please sign here. No one will ever know your name because of this code. We can begin now with the questions.

The purpose of this study is to identify and report the lived experiences of senior leaders in servant leadership organizations in the southwestern United States. The following questions list the criteria set forth by Greenleaf $(1977,2002)$ for effective high-performance organizations and employee engagement.

Central Research Question: What are the lived experiences of leaders in servant leadership organizations in the southwestern United States?

Q1. What are your perceptions of the culture that is prevalent in your organization regarding leadership? Based on your perceptions and experiences:

1. How have you experienced these organizational criteria?
(a) Service: a willingness to serve
(b) Inspiring and caring mechanism employed
(c) Other-oriented management
(d) Ethics
(e) Builds community
(f) Stewardship
(g) Profitability
(h) Sustainability
(i) Foster innovation

2. How have you experienced the leadership in the organization?

3 . How have you experienced the culture of the organization?

4. How have you experienced the structures/systems of the organization?

Q2. What are your assumptions about the leaders of your organization regarding their individual attributes such as virtues/values, behaviors, and attitudes? Based on your perceptions and experiences, what individual attribute is prevalent in the organization?

1. How have you experienced these virtues/values?
(a) Compassion
(b) Empathy
(c) Spirituality
(d) Healing
(e) Ethics/integrity
(f) Service

2. How have you experienced these behaviors?
(a) Listening
(b) Inspiring
(c) Empowering
(d) Sharing/caring
(e) Building
(f) Mentoring 
3. How have you experienced these attitudes?
(a) Positive (can do)
(b) Collaborative
(c) Cooperative

4. How, based on your experiences, have these individual attributes contributed to or influenced employee engagement?

Q3. What do you believe are the reasons that prevent your leaders from achieving even higher levels of organizational performance excellence? Based on your perceptions and experiences,

1. What are the mindsets that impede, detract, make difficult, or prevent SL practice?

2. How have you experienced nonservant leaders in the organization?

3. How have you experienced the mentoring program in the organization?

4. How have you experienced the organization managing the fear of change?

5 . How have you experienced the meaning of the word servant?

6. How have you experienced short-term organizational goals as barriers to SL practice?

7. What else, based on your perceptions and experiences, impedes, detracts, makes difficult, or prevents the practice of SL?

This is the end of the questions. Thank you for participating in this study. You are welcome to look at my notes. I will send a copy of the transcript to you by email within a few days to check for accuracy. Please send the transcript back within 48 hours, if possible; if not, I will assume it is accurate. It has been a pleasure meeting with you. Thanks again for your cooperation.

The Journal of Social Change, sponsored by Walden University, welcomes manuscripts focusing on interdisciplinary research in social change that improves the human condition and moves people, groups, organizations, cultures, and society toward a more positive future.

Walden University Publishing: http://www.publishing.waldenu.edu 